\title{
IQ driving QI: the Asia Pacific Consortium on Osteoporosis (APCO): an innovative and collaborative initiative to improve osteoporosis care in the Asia Pacific
}

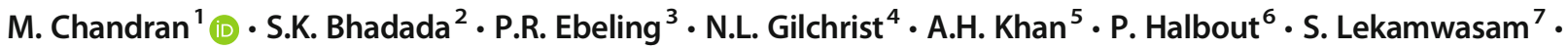 \\ G. Lyubomirsky ${ }^{8}$ P.J. Mitchell ${ }^{9} \cdot$ T.V. Nguyen ${ }^{10,11} \cdot$ K.L. Tiu ${ }^{12}$ • \\ on behalf of the Asia Pacific Consortium on Osteoporosis
}

Received: 15 April 2020 / Accepted: 4 June 2020 / Published online: 19 June 2020

(C) The Author(s) 2020

\begin{abstract}
Summary Asia Pacific Consortium on Osteoporosis (APCO) comprises of clinical experts from across the Asia Pacific region, uniting to develop solutions to problems facing osteoporosis management and care. The vision of APCO is to reduce the burden of osteoporosis and fragility fractures in the Asia Pacific region.

Introduction The Asia Pacific (AP) region comprises 71 countries with vastly different healthcare systems. It is predicted that by 2050, more than half the world's hip fractures will occur in this region. The Asia Pacific Consortium on Osteoporosis (APCO) was set up in May 2019 with the vision of reducing the burden of osteoporosis and fragility fractures in the AP region.

Methods APCO has so far brought together 39 clinical experts from countries and regions across the AP to develop solutions to challenges facing osteoporosis management and fracture prevention in this highly populous region of the world. APCO aims to achieve its vision by engaging with relevant stakeholders including healthcare providers, policy makers and the public. The initial APCO project is to develop and implement a Framework of pan-AP minimum clinical standards for the screening, diagnosis and management of osteoporosis.

Results and conclusions The Framework will serve as a platform upon which new national clinical guidelines can be developed or existing guidelines be revised, in a standardised fashion. The Framework will also facilitate benchmarking for provision of quality of care. It is hoped that the principles underlying the formation and functioning of APCO can be adopted by other regions and that every health care facility and progressively every country in the world can follow our aspirational path and progress towards best practice.
\end{abstract}

Keywords Osteoporosis $\cdot$ Fragility fracture $\cdot$ Quality improvement $\cdot$ Clinical standards $\cdot$ Collaboration $\cdot$ Asia Pacific

A fragility fracture signals underlying osteoporosis, a condition that is greatly underdiagnosed and undertreated. The burden of osteoporosis is expected to increase as populations age, and the number of individuals at risk of fragility fractures
M. Chandran

manju.chandran@singhealth.com.sg

1 Osteoporosis and Bone Metabolism Unit, Department of Endocrinology, Singapore General Hospital, 20 College Road, Singapore 169856, Singapore

2 Postgraduate Institute of Medical Education and Research (PGIMER), Chandigarh, India

3 Department of Medicine, School of Clinical Sciences, Monash University, Melbourne, Australia

4 Canterbury District Health Board, Christchurch, New Zealand

\footnotetext{
Aga Khan University, Karachi, Pakistan

6 International Osteoporosis Foundation, Nyon, Switzerland

7 University of Ruhuna, Matara, Sri Lanka

8 Osteoporosis Australia, Sydney, Australia

9 Synthesis Medical NZ Limited, Auckland, New Zealand

10 The Garvan Institute of Medical Research, Sydney, Australia

11 University of Technology, Sydney, Australia

12 Queen Elizabeth Hospital, Hong Kong, Hong Kong SAR
} 
worldwide is estimated to increase more than twofold from the 158 million it was in 2010 to 319 million by the year 2040 [1]. Unfortunately, even the patients at highest risk who have already fractured are often not treated $[2,3]$. The situation, in the Asia Pacific region, which is home to 4.5 billion people and comprises 71 countries and regions [4] is going to be even more overwhelming. The population aged over 65 years in Asia alone is projected to more than quadruple by 2050, and to further grow by almost sixfold by the year 2100 [5]. It is predicted that in the year 2050, over half of the world's hip fractures will be in the Asia Pacific region [6]. This will come at great cost; treating a single hip fracture represents approximately $19 \%$ of Asia Pacific's regional per-head gross domestic product each year even currently $[7,8]$.

Despite the enormous and growing burden of fragility fractures, osteoporosis is being dangerously ignored as it competes with other diseases for scarce health-care resources and recognition. The disease remains greatly under-diagnosed and under-treated, and health professional training and service provision is suboptimal in many countries of the Asia Pacific. - Professor John Kanis, Honorary President, International Osteoporosis Foundation (IOF) at the launch of the Asia Pacific Regional Audit Report, 2013 [9]

This statement comes as no surprise since the Asia Pacific region has within it, populations with tremendously diverse socio-economic and cultural norms and countries with vastly different health systems and resources. The healthcare responses to osteoporosis are thus fragmented and unequal. Added challenges include variations in knowledge and disease awareness, limited diagnostic facilities and lack of health professionals trained in osteoporosis management in several countries in the region $[3,10,11]$.

\section{The Asia Pacific Consortium on Osteoporosis}

The Asia Pacific Consortium on Osteoporosis (APCO), a nonpartisanal and apolitical organization, was established in May 2019 with the vision of reducing the burden of osteoporosis and fragility fractures in the Asia Pacific region. APCO hopes to achieve this vision by engaging with relevant stakeholders including healthcare providers, policy makers and the public, to help develop and implement country and region-specific programs for the prevention and treatment of osteoporosis and its complication of fragility fractures in the Asia Pacific region.

The idea for developing a consortium on osteoporosis was inspired by similar work in another area of clinical medicine. The primary aim at the time of the formation of APCO was to gather a group of experts whose work to date has demonstrated their passion and commitment to advancing the cause of osteoporosis in their respective countries and/or in the region. These individuals were identified and invited by the Chairperson to contribute their expertise to APCO. APCO members voluntarily contribute their time and expertise to it. The strength of APCO lies in the diversity of its members, with it creating a forum for the exchange of ideas between experts working in very different healthcare systems and clinical settings. APCO is also ably supported in its functions by a four-member project management team.

APCO currently has 39 experts from 19 countries and regions within the Asia Pacific. The International Osteoporosis Foundation (IOF) is represented by its Chief Executive Officer. We hope to ultimately include osteoporosis experts from all the countries and regions in the Asia Pacific. APCO endeavours to support and empower healthcare professionals to improve osteoporosis care, and its members will serve as a bridge between APCO and their colleagues, thought leaders, osteoporosis societies and policy makers within their respective countries.

\section{The priority initiative of APCO}

Adherence to evidence-based management recommendations is associated with improvement in patient outcomes [12]. Strategies employed to improve the implementation and use of osteoporosis guidelines have also been shown to result in management plans becoming aligned with best practice [13]. APCO has identified the following key gaps in osteoporosis screening, diagnosis and in consistent delivery of osteoporosis care in the Asia Pacific region:

- Clinical guidelines relating to osteoporosis in the Asia Pacific are either unavailable and if they are, are heterogenous in terms of their scope and recommendations made.

- A significant proportion of current national guidelines are not current, having been published more than 10 years ago.

- There is a paucity of information on adherence with national guidelines in day-to-day clinical practice across the region.

Therefore, APCO's first project is to develop and implement a Pan-Asia Pacific framework ("The Framework") that provides clinical standards for the screening, diagnosis and management of osteoporosis in groups at high risk of fracture. Broad endorsement of the Framework will be sought from national and international organizations before publication of the Framework. Subsequently, APCO will also provide tools and templates to support its members to deliver the Framework at the local level. The long-term goal after publication of the Framework is to develop APCO into a freestanding entity with a formalized legal, governance and organizational structure. 


\section{The nitty-gritties of developing The Framework}

The framework focuses on identifying and treating a broad range of high-risk groups in a tiered manner. The highest priority group is older men and post-menopausal women with a prevalent fragility fracture. The other groups that are included in the Framework are people taking medications and/or have medical conditions that predispose them to bone loss or fragility fracture, people deemed to be at high risk based on countryspecific fracture intervention thresholds, those aged 70 years or over and those below 70 years of age with other risk factors for fragility fracture, such as a history of frequent falls.

A stepwise approach informed by analogous approaches undertaken elsewhere [14] is being employed to develop the Framework. All osteoporosis and fracture prevention guidelines published in the last decade in the Asia Pacific region have been identified and those in other languages have been translated into English. A comparative analysis of the guidelines with special attention to the ones published in the last quinquennium has been done using a template based on a modified "5IQ" approach. The "5IQ" approach underpinned the development of clinical standards for Fracture Liaison Services (FLS) in New Zealand [15] and the UK [16]. Each guideline that was included in the comparative analysis was thoroughly evaluated to see whether the following 6 parameters were included in it:

- Identification: a statement regarding which individuals are identified as high risk

- Investigation: a description of the types of investigations recommended to delineate the cause of osteoporosis

- Information: a description of the types of education that are provided

- Initiation: a description of pharmacological and falls prevention interventions

- Integration: a statement on the need for integration between primary and secondary care

- Quality: a description of professional development, audit and peer-review activities

The comparative analysis has now been completed. The minimum standards of care that will form the framework will be generated through a Delphi process [17] to identify areas of consensus and discord amongst the APCO members.

The Framework will serve as a platform upon which new national clinical guidelines in the Asia Pacific can be developed or existing guidelines be revised, in a standardized fashion. Practical adoption of the clinical standards at each national level is the ultimate purpose for developing the Framework. Notably, the Framework will be a distilled guidance document with minimum clinical standards for best practice, not a prescriptive guideline.
To address the heterogeneity across the region, the Framework and its implementation will be modular, allowing the user to select the most appropriate content depending on the stage or level already attained by their facility or country. A stepwise path for progression towards best practice will be set, and each facility will be encouraged to progress to the next level as they are able to. This modular approach is similar to the Capture the Fracture ${ }^{\circledR}$ Best Practice Framework that has been implemented by the IOF and to the patient-level key performance indicators recently endorsed by the National Osteoporosis Foundation and the Fragility Fracture Network [18, 19].

For each country or region, an assessment of the differences between the core recommendations of current national clinical guidelines and the standards advocated in the Framework will inform the improvements that need to be made at the national /regional level. This can then serve as an impetus to advocate for and to drive policy change. To realise these changes, APCO will be collaborating with national, regional and international societies and organizations such as the Asian Federation of Osteoporosis Societies, the Fragility Fracture Network, the Asia Pacific Fragility Fracture Alliance and the International Osteoporosis Foundation and educational initiatives such as the Asia Pacific Bone Academy [20]. We envision these collaborations to be seamless as many of the APCO members are already part of these organisations and initiatives.

Implementation of the Framework and its effectiveness needs to be measured for it to be meaningful. The medical centres where APCO members work at will serve as "pathfinder" sites for their respective countries. Immediately after publication of the Framework, an audit will be conducted at pathfinder sites to assess how congruent their own standards of care are with those advocated in the Framework. A followup audit can then be conducted by pathfinder sites 12 months after the baseline audit, to assess the impact of the Framework.

In the words of the Chinese philosopher, Lao Tzu (老 子《道德經), “The journey of a thousand miles starts with one step” (“「千里之行, 始於足下」”). There is no doubt that there is a long way to go to reduce the burden of osteoporosis and fragility fractures in the Asia Pacific region. The development of the Framework of minimum clinical standards is the first step to improve the screening, diagnosis and management of osteoporosis in groups at high risk of fracture in this region. APCO's intention is not to ignore current stark realities and the challenges and limitations that make osteoporosis care difficult in such a vast and diversely populated area such as the Asia Pacific, but to provide a benchmark to which organizations and health care facilities can aspire. The principles underlying the formation and functioning of APCO could potentially be adopted by other regions in the world. It is hoped that each facility and progressively each country will follow 
our aspirational path towards best practice, ultimately making osteoporosis a national, regional and international health priority to avert the "perfect storm" [3] that is brewing.

Acknowledgements APCO gratefully acknowledges the contribution by Professor John Eisman AO (The Garvan Institute of Medical Research, Sydney, Australia) who laid the groundwork for initial discussions regarding the formation of the consortium. APCO also gratefully acknowledges Dr. Cae Tolman, Regional Medical Director, Bone Health, Amgen Asia and current pharmaceutical industry representative to the EXCO for his invaluable support in setting up APCO and promoting its cause. Editorial assistance was provided by Dr. Yoonah Choi of Evidencia Medical Communications Pty Ltd., contracted by APCO for the purpose.

APCO Members: T. Amphansap, Police General Hospital, Bangkok, Thailand; L. Asis, University of the Philippines, Manila, Philippines; S. K. Bhadada, Postgraduate Institute of Medical Education and Research (PGIMER), Chandigarh, India; D.C. Chan, National Taiwan University Hospital, Taiwan; M. Chandran, Osteoporosis and Bone Metabolism Unit, Singapore General Hospital, Singapore; M. Chadha, Hinduja Hospital and Research Centre, Mumbai, India; T.T. Chit, Yangon General Hospital, Yangon, Myanmar; Y. S. Chung, Ajou University School of Medicine, Suwon, Republic of Korea; H. Doshi, Gleneagles Medical Centre, Singapore, Singapore; P.R. Ebeling, Monash University, Melbourne, Australia; N. L. Gilchrist, Canterbury District Health Board, Christchurch, New Zealand; F.L. Hew, Puchong Medical Specialist Centre and Subang Jaya Medical Centre, Malaysia; A. Habib Khan, Aga Khan University, Karachi, Pakistan; P. Halbout, International Osteoporosis Foundation, Nyon, Switzerland; L. Ho-Pham, Pham Ngoc Thach University of Medicine, Ho Chi Minh City, Vietnam; T.S. Latt, Shwe Baho Hospital, Yangon, Myanmar; E. Lau, Hong Kong Orthopaedic and Osteoporosis Center for Treatment and Research, Hong Kong, Hong Kong SAR; T.C. Lau, National University Hospital, Singapore, Singapore; D.O. Lee, National Cancer Center, Goyang, Republic of Korea; J.K. Lee, Beacon Hospital, Petaling Jaya, Malaysia; S. Lekamwasam, University of Ruhuna, Matara, Sri Lanka; J. Liu, Shanghai Ruijin Hospital, Shanghai, China; G. Lyubomirsky, Osteoporosis Australia, Sydney, Australia; A. Mithal, Max Healthcare, Saket, New Delhi, India; P.J. Mitchell, Synthesis Medical NZ Limited, Auckland, New Zealand; T.V. Nguyen, The Garvan Institute of Medical Research, Sydney, Australia and University of Technology, Sydney, Australia; D. Pandey, National Trauma Centre, Kathmandu, Nepal; I. Reid, University of Auckland, Auckland, New Zealand; K. H. Rhyu, Kyung Hee University, Seoul, Republic of Korea; A. Suzuki, Fujita Health University, Toyoake, Japan; A. Taguchi, Matsumoto Dental University, Nagano, Japan; V. T. Thuy, Bach Mai Hospital, Hanoi, Vietnam; G. Tirtarahardja, Indonesian Osteoporosis Association (PEROSI), Jakarta, Indonesia; K.L. Tiu, Queen Elizabeth Hospital, Hong Kong, Hong Kong SAR; C. Tolman, Amgen Asia, Hong Kong, Hong Kong SAR; T. Vallenukal, Bhumibol Adulyadej Hospital, Bangkok, Thailand; W. Xia, Peking Union Medical College Hospital, Beijing, China; C.K. Yung, Raja Isteri Pengiran Anak Saleha Hospital, Bandar Seri Begawan, Brunei Darussalam; Y. Zhao, Beijing United Family Hospital, Beijing, China.

Funding information Amgen Asia provided financial support to fund secretariat function, event management and communication activities for the formation of APCO.

\section{Compliance with ethical standards}

Disclaimer The opinions and activities of APCO are not influenced by Amgen, nor did Amgen have any role in the writing of this opinion piece.
Conflict of interest Dr. Manju Chandran has received honoraria for lectures and sponsorships for conferences from Eli Lilly and Amgen.

Professor Peter Ebeling has research funding from Amgen, Eli-Lilly, Novartis and Alexion and has received honoraria from Amgen and Alexion.

Paul Mitchell (PM) has undertaken consultancy for governments, national and international osteoporosis societies, healthcare professional organisations and private sector companies relating to systematic approaches to fragility fracture care and prevention since 2005. PM serves as APCO Project Manager on a paid consultancy basis.

Professor Tuan Nguyen has received grant support from Amgen and honoraria for lectures and conference engagements from Novartis, MSD, Amgen and Bridge Health Care.

Drs Sanjay Bhadada, Nigel Gilchrist, Aysha Habib Khan, Philippe Halbout, Sarath Lekamwasam, Greg Lyubomirsky and Kwok Leung Tiu declare that they have no conflict of interest.

Open Access This article is licensed under a Creative Commons Attribution-NonCommercial 4.0 International License, which permits any non-commercial use, sharing, adaptation, distribution and reproduction in any medium or format, as long as you give appropriate credit to the original author(s) and the source, provide a link to the Creative Commons licence, and indicate if changes were made. The images or other third party material in this article are included in the article's Creative Commons licence, unless indicated otherwise in a credit line to the material. If material is not included in the article's Creative Commons licence and your intended use is not permitted by statutory regulation or exceeds the permitted use, you will need to obtain permission directly from the copyright holder. To view a copy of this licence, visit http:// creativecommons.org/licenses/by-nc/4.0/.

\section{References}

1. Oden A, McCloskey EV, Kanis JA, Harvey NC, Johansson H (2015) Burden of high fracture probability worldwide: secular increases 2010-2040. Osteoporos Int 26(9):2243-2248

2. Australian and New Zealand Hip Fracture Registry (2019) ANZHFR Annual Report of Hip Fracture Care 2019. https:// anzhfr.org/wp-content/uploads/2019/09/2019-ANZHFR-AnnualReport-FINAL.pdf. Accessed 27 March 2020

3. Yeap SS, Jaisamrarn U, Park YS, Takeuchi Y, Xia W, Committee AC-T-A (2017) The Asian Federation of Osteoporosis Societies' call to action to improve the undertreatment of osteoporosis in Asia. Osteoporos Sarcopenia 3(4):161-163

4. United Nations Department of Economic and Social Affairs Population Division World population prospects: the 2017 revision, key findings and advance tables. Working Paper No. ESA/ P/WP.248. New York. 2017

5. United Nations Department of Economic and Social Affairs Population Division Infographics, Ageing population - Projected global population aged 60 years or over: 2017 revision

6. Cheung CL, Ang SB, Chadha M, Chow ES, Chung YS, Hew FL, Jaisamrarn U, Ng H, Takeuchi Y, Wu CH, Xia W, Yu J, Fujiwara S (2018) An updated hip fracture projection in Asia: the Asian Federation of Osteoporosis Societies study. Osteoporos Sarcopenia 4(1):16-21

7. Mohd-Tahir NA, Li SC (2017) Economic burden of osteoporosisrelated hip fracture in Asia: a systematic review. Osteoporos Int 28(7):2035-2044

8. The Economist Intelligence Unit (2017) Demystifying ageing: lifting the burden of fragility fractures and osteoporosis in AsiaPacific. https://perspectives.eiu.com/sites/default/files/ Demystifying ageing Lifting the burden of fragility fractures and_osteoporosis_in_Asia_Pacific_0.pdf. Accessed 3 April 2020 
9. International Osteoporosis Foundation Asia Pacific must prepare for catastrophic increase in fragility fractures. Media release 12 December 2013. https://www.iofbonehealth.org/news/asia-pacificmust-prepare-catastrophic-increase-fragility-fractures. Accessed 23 March 2020

10. International Osteoporosis Foundation The Asia-Pacific Regional Audit: epidemiology, costs and burden of osteoporosis. https:// www.iofbonehealth.org/sites/default/files/media/PDFs/Regional $\%$ 20Audits/2013-Asia_Pacific_Audit-Key_Findings_0_0.pdf. Accessed 13 February 2020

11. Osteoporosis National Action Plan Working Group (2016) Osteoporosis National Action Plan 2016. https://www. osteoporosis.org.au/sites/default/files/files/Osteoporosis\% 20National\%20Action\%20Plan\%202016.pdf. Accessed 3 April 2020

12. Ganda K, Puech M, Chen JS, Speerin R, Bleasel J, Center JR, Eisman JA, March L, Seibel MJ (2013) Models of care for the secondary prevention of osteoporotic fractures: a systematic review and meta-analysis. Osteoporos Int 24(2):393-406

13. Kimber CM, Grimmer-Somers KA (2009) Multifaceted guideline implementation strategies improve early identification and management of osteoporosis. Aust Health Rev 33(3):423-433

14. Kanis JA, Cooper C, Rizzoli R, Reginster JY, Scientific Advisory Board of the European Society for Clinical and Economic Aspects of Osteoporosis and Osteoarthritis (ESCEO) and the Committees of Scientific Advisors and National Societies of the International Osteoporosis Foundation (IOF) (2019) Executive summary of European guidance for the diagnosis and management of osteoporosis in postmenopausal women. Aging Clin Exp Res 31(1):15-17

15. Osteoporosis New Zealand (2017) Clinical standards for fracture liaison services in New Zealand. http://osteoporosis.org.nz/wp-
content/uploads/FLS-July-2017-Clinical-Standards-WEB.pdf. Accessed 3 April 2020

16. Royal Osteoporosis Society (2019) Effective secondary prevention of fragility fractures: clinical standards for fracture liaison services. https://theros.org.uk/media/1 eubz33w/ros-clinical-standards-forfracture-liaison-services-august-2019.pdf. Accessed 3 April 2020

17. Wikipedia (2019) Delphi method. https://en.wikipedia.org/wiki/ Delphi_method. Accessed 15 March 2019

18. Javaid MK, Kyer C, Mitchell PJ, Chana J, Moss C, Edwards MH, McLellan AR, Stenmark J, Pierroz DD, Schneider MC, Kanis JA, Akesson K, Cooper C, the International Osteoporosis Foundation Working Group (2015) Effective secondary fracture prevention: implementation of a global benchmarking of clinical quality using the IOF capture the fracture(R) best practice framework tool. Osteoporos Int 26(11):2573-2578

19. Javaid MK, Sami L, Lems W, Mitchell P, Thomas T, Singer A, Speerin R, Fujita M, Pierroz DD, Akesson K, Halbout P, Ferrari S, Cooper C (2020) A patient-level key performance indicator set to measure the effectiveness of fracture liaison services and guide quality improvement: a position paper of the IOF capture the fracture working group, National Osteoporosis Foundation and Fragility Fracture Network. Osteoporos Int. https://doi.org/10. 1007/s00198-020-05377-1

20. Ebeling PR, Chan DC, Lau TC, Lee JK, Songpatanasilp T, Wong SH, Hew FL, Sethi R, Williams M (2020) Secondary prevention of fragility fractures in Asia Pacific: an educational initiative. Osteoporos Int 31(5):805-826

Publisher's note Springer Nature remains neutral with regard to jurisdictional claims in published maps and institutional affiliations. 